\title{
Triadic interactions in families with preterm children: a comparative study with children born at term
}

This article was published in the following Dove Press journal:

Neuropsychiatric Disease and Treatment

13 September 2017

Number of times this article has been viewed

\author{
Michela Gatta ${ }^{1,2}$ \\ Marina Miscioscia ${ }^{2,3}$ \\ Lorenza Svanellini² \\ Maria Elena Brianda ${ }^{3}$ \\ Giada Guerra ${ }^{3}$ \\ Pier Antonio Battistella ${ }^{2}$ \\ Alessandra Simonelli ${ }^{3}$ \\ 'Childhood Adolescence Family \\ Unit AULSS 6 Veneto, ${ }^{2}$ Department \\ of Women's and Children's Health, \\ ${ }^{3}$ Department of Developmental \\ Psychology and Socialization, \\ University of Padova, Padova, Italy
}

Correspondence: Michela Gatta Department of Women's and Children's Health, University of Padova, 3 Via Giustiniani, Padova 35।28, Italy Email michela.gatta@unipd.it

\begin{abstract}
The relationship between parents and infants born preterm is multifaceted and could present some relational patterns which are believed to predict psychological risk more than others. For example, insensitive parenting behavior has been shown to place very preterm children at greater risk of emotional and behavioral dysregulation. The main objective of this study was to compare the quality of family interactions in a sample of families with preterm children with one of the families with at-term children, exploring possible differences and similarities. The second aim of this research was to consider the associations among family interactions and parental empowerment, the child's temperament, parenting stress, and perceived social support. The sample consisted of 52 children and their families: 25 families, one with two preterm brothers with preterm children (mean 22.3 months, SD 12.17), and 26 families with children born at term (mean 22.2 months, SD 14.97). The Lausanne Trilogue Play procedure was administered to the two groups to assess the quality of their family interactions. The preterm group was also administered the Questionari Italiani del Temperamento, the Family Empowerment Scale, the Multidimensional Scale of Perceived Social Support, and the Parenting Stress Index - Short Form. Differences in the quality of family interactions emerged between the preterm and at-term groups. The preterm group showed significantly lower quality of family interactions than the at-term group. The parenting stress of both parents related to their parental empowerment, and maternal stress was also related to the partner's parental empowerment. Social support had a positive influence on parenting stress, with maternal stress also related to perceived social support from the partner, which underscores the protective role of the father on the dyad.
\end{abstract}

Keywords: family interactions, preterm birth, parenting, Lausanne Trilogue Play

\section{Introduction}

The World Health Organization classifies prematurity based on gestational age (GA) as extremely preterm ( $<28$ weeks), very preterm $(28<\mathrm{GA}<32$ weeks $)$, and moderate-late preterm $(>32-<37$ weeks $) .{ }^{1}$ Preterm birth rates are increasing in almost all countries with reliable data. ${ }^{1}$ In Italy, the latest report from the Ministry of Health (published in 2012) discusses data collected in 2008, when the percentages of babies born before the 37 th and before the 32 nd week of gestation were $6.8 \%$ and $0.9 \%$, respectively. ${ }^{2}$

The immaturity of preterm newborns exposes them to multiple, complex medical problems that demand a lengthy stay in neonatal intensive care units. The stress and painful procedures of this unphysiological extrauterine environment affect the immature nervous system of preterm newborns, giving rise to a different trajectory in their neurobehavioral development ${ }^{3,4}$ and a greater risk of disorders later on. . $^{5,6}$ 
The existing literature has explored the preterm child's development in depth. Studies report cognitive impairments, namely, a lower IQ than term-born children, ${ }^{5,7-9}$ even when they are within the normal range. ${ }^{10,11}$ The difference depends on their GA at birth: ${ }^{7,12}$ their IQ declines by a mean 2.5 points for every week's decrease in GA, starting from the 33rd week. ${ }^{7}$ Executive functions, attention, and linguistic and communicative skills are other areas of weakness ${ }^{13-20}$ not explained by a general cognitive deficit.

According to studies that have considered motor development, preterm children whose intelligence is within the normal range could still encounter gross and fine motor delays ${ }^{8}$ that interfere with their exploration of the environment, writing abilities, and involvement in social activities, becoming a risk factor for future cognitive and learning abilities and for behavioral problems. ${ }^{21}$

On the subject of their behavioral and emotional development, preterm infants may show weak relational, emotional, and social competence; difficult self-regulation of behavior and emotions; and a limited attention span already in the early stages of their development. ${ }^{22}$ Their impaired social skills negatively affect their socialization ability and their capacity to handle peer relationships. It is also worth noting that most studies have reported that very preterm children show higher mean scores on socioemotional scales than their term-born peers, though not reaching clinical cutoff scores. ${ }^{6}$ As for the temperament construct, an Italian sample of 105 children (mean age 5 years and 2 months) born before the 32 nd week of gestation showed a mainly normal profile for the Italian culture, but they also revealed some peculiarities: apart from positive emotionality (where they scored significantly higher than children born at term), the preterm group showed lower levels of motor control and attention, negative emotional reactivity and social orientation, and inhibition to novelty, although the differences in their scores did not reach statistical significance..$^{23}$

Another aspect examined in the literature is parental distress, given the stressful experience and concern for their child's health and the fact that preterm delivery interrupts the transition to parenthood. The mother's psychological suffering has been studied more, but more attention has recently been paid to the father because of his stronger involvement in the event of premature birth. ${ }^{24,25}$

Immediately after a preterm birth, $40 \%$ of mothers show symptoms of postpartum depression, as opposed to $10 \%-15 \%$ of mothers giving birth at term ${ }^{26}$ and they generally suffer from postpartum stress. ${ }^{27}$ State anxiety is also higher after a preterm birth, due to the mother's persistent and continuous apprehension for the health of their child, perceived as vulnerable. ${ }^{28}$ Even in the case of late prematurity (at 32-37 weeks of gestation), the mothers of preterm infants display higher levels of depression and anxiety than the mothers of infants born at term when assessed 6 months after the delivery, whereas this was not the case 2 months after the delivery. ${ }^{29}$

Mothers' psychological stress is often associated with some degree of comorbidity. Shaw et $\mathrm{al}^{30}$ found that $77.8 \%$ of preterm infants' mothers had at least one symptom attributable to depression, ${ }^{31-33}$ anxiety, ${ }^{34}$ or post-traumatic syndrome, ${ }^{35,36}$ and $51 \%$ had symptoms attributable to at least two of these conditions. Given the strong emotional experience in the period of transition to parenthood, some authors have focused on assessing the stress related to parenting. When parenting stress was assessed with the Parenting Stress Index - Short Form (PSI-SF) ${ }^{37}$ in mothers of 12-month-old children (corrected age), those whose offspring were born prematurely experienced twice as much stress as the mothers of those born at term. The difference emerged mainly on parent-infant dysfunctional interaction, suggesting that mothers of preterm babies had more difficulty in connecting to their child. ${ }^{38}$ Olafsen et al ${ }^{39}$ discovered a deep association between parenting stress and negative reactive temperament in 1-year-old children.

Research has found that parents' psychological distress can show determinant effects on infants and children, including impaired parent-infant interaction quality, ${ }^{40,41}$ which can in turn result in different consequences on infant development, such as behavioral dysregulation and impaired language, cognitive, and motor development. ${ }^{41-43}$ In particular, the relationship between child and parents is paramount in providing the foundation for self-regulation capacities and for both relational-affective and cognitive development. ${ }^{44,45}$ In fact, infant cognitive development appears to be related to parent-infant interactions, in particular to parent sensitivity and touch, from the parent's ability to verbalize infant affective states; these parental interactive skills can all be exacerbated by distress. ${ }^{43,46-48}$ Santos et $\mathrm{al}^{49}$ found that mothers under extreme psychological distress displayed more positive involvement and cognitive stimulation, in order to compensate for the lack of interactive behavior from a sick or at-risk infant. ${ }^{50} \mathrm{~A}$ recent study of Montirosso et al ${ }^{50}$ found differential brain activation patterns in mothers of preterm children. With regard to fathers, $10 \%$ (versus $20 \%$ of mothers) met the criteria for an adjustment disorder and had more severe symptoms of anxiety, ${ }^{34}$ depression, ${ }^{51}$ and post-traumatic syndrome, which appeared later in fathers 
(4 months after their child's birth, they were more at risk than the mothers). This could be because the father needs to concentrate initially on sustaining the mother, who is more fragile and vulnerable in the early period after the birth. ${ }^{36}$

Despite this evidence, these aspects have been less examined in the literature from a triadic point of view. Infant medical risk may compound the effects of a preterm birth on parental and infant functioning and the quality of parent-infant interaction. In such situations, social support is a protective factor for both parents' well-being and mental health, since it can reduce the parents' stress. ${ }^{53-55}$ Actually, mean values for perceived social support of "preterm parents" have been found to be 5 points higher than "at-term parents", underscoring its importance in the case of high-level stress. ${ }^{54}$ Singer et $\mathrm{al}^{55}$ also found that the extremely stressful conditions relating to the preterm birth do not decrease the adults' self-perception of competence as parents.

In this regard, family empowerment has been identified as an important indicator in families with at-risk children, ${ }^{56,57}$ but it has been studied less in families with preterm children, in particular after parents leaving the neonatal intensive care unit. Given the aforementioned intrinsic risk factors involving the parents and their child, some studies have focused on the parent-preterm child relationship, specifically exploring the interaction. Prematurity has a negative influence on interactive, communicative, and expressive mother-child behaviors during the first years of life..$^{58,59}$

As a party in this interaction, the preterm child is seen as more passive, ${ }^{60-62}$ less alert and focused, ${ }^{62,63}$ and less responsive. ${ }^{64-66}$ They are less inclined to make eye contact with their mother ${ }^{67-69}$ and may be less vocal, ${ }^{66,70}$ or more vocal, ${ }^{71}$ but with less contingency. ${ }^{64}$ They have less well-developed self-regulatory competence, ${ }^{72}$ smile less, ${ }^{73}$ and are generally characterized by the expression of more negative affect ${ }^{62,67,74,75}$ than infants born at term. According to some studies, preterm infants also find it more difficult to give clear clues to caregivers. ${ }^{76,77}$

In this context, concerning maternal behavior, studies have generally found that the maternal interactive style is more directive, active, and controlling at 3 months, ${ }^{60,63,70,71}$ and mothers tend to be less sensitive, ${ }^{60,70}$ using a directive scaffolding ${ }^{78,79}$ with a contradictory style alternating passive and overstimulating exchanges. ${ }^{80}$

As for preterm parenting behavior, so far studies have generated inconsistent and contradictory results, ${ }^{58,59}$ possibly due in part to the tools used to assess interactions and to the heterogeneity of the samples considered. ${ }^{81}$ Some studies found parents of preterm infants to be sensitive and responsive, ${ }^{68,74,82}$ but tending to express responsiveness verbally more than in their facial expressions. ${ }^{71}$ They use social monitoring and eye $\operatorname{contact}^{81}$ and positive affect expressed verbally and nonverbally, ${ }^{72}$ although birth weight influences the intrusiveness of mothers. ${ }^{81}$

In summary, the literature has identified a particular interactive style in preterm dyads, characterized by more passive exchanges with few infant initiatives. Some authors attribute this characteristic to maternal intrusiveness, while others state that such maternal intrusiveness represents in truth greater reactivity aimed at compensating for the child's developmental inadequacy. ${ }^{58,69} \mathrm{~A}$ recent study found that the experience of joint attention did not lead to positive developmental outcomes when the child was not actively involved. ${ }^{18}$

With regard to affection, while studies involving a heterogeneous group of preterm children found no differences, ${ }^{72,74}$ other research observed that children were born extremely preterm and their mothers mainly expressed neutral emotions during interactive exchanges. ${ }^{18}$ Finally, some authors have made the point that certain aspects characteristic of interaction with preterm children become gradually clearer after the first 6 months of the child's life, when the environment becomes more complex and demanding. ${ }^{65,70,74,83}$ Feldman and Eidelman ${ }^{76}$ also pointed out that a mother's postpartum interactive behavior predicts both maternal and paternal future interactive synchrony with their child.

As for the father's role, few studies have observed father strategies of interaction with the preterm child. As in the case of the mother, this interaction is of poorer quality than when a child is born at term. ${ }^{84}$ There is less dyadic reciprocity, and the parent has more difficulty adapting to the child's timing and rhythms, ${ }^{85}$ with fewer moments of joint attention ${ }^{86}$ and less eye contact synchrony. ${ }^{76}$ Although many authors recommend assessing triadic interaction in families with children born preterm, ${ }^{18,87,88}$ few studies have adopted a method for observing the triad in interactions. Higher levels of rigidity and lower levels of cohesion have been found in families with very low-birth-weight or intrauterine growth restriction children compared to control families. ${ }^{85}$ Only one recent study used the Lausanne Trilogue Play (LTP), ${ }^{89}$ the observational method selected for the purposes of the present research. In that study, only seven variables (regarding affect sharing, timing/synchronization, and child behavior) of the LTP were used to examine the interaction in 83 families with 6-monthold healthy children born between the 28th and 34th weeks of gestation, ${ }^{90}$ and no differences emerged from comparison with a normative group. This interesting study is one of the few published in the literature to have investigated the 
moderating role of family dynamics in the development of preterm children. It was also the first to use the LTP approach to assess this construct. The study only partially considered family interactions, though, because they were not the main focus of the study. It thus seems worthwhile to explore triadic interactions after the first 6 months of life, given that there are reports in the literature of differences subsequently emerging in the dyadic interactive style of parents and their preterm child.

Our literature review brought to light the shortage of specific studies on the role of family interactions in the preterm child's development. The effect of distress on parent-children interactions, as well as the importance of social support and family empowerment as mediators, has been discharged, but still little has been deepened at the level of parent-child interactions; furthermore, fathers have been little involved as the focus of study. The family is the primary child's context of socialization, and empirical research has shown that family interactions are predictive of several child development outcomes. Given these reasons, research on an at-risk population needs to be extended, and this is the specific area that our study aimed to approach.

\section{Aims}

This paper aims to contribute to the literature on family interactions in families with children born preterm. To date, no sufficient literature has observed the quality of such family interactions as a whole. The literature has concentrated more on certain components, such as parental scaffolding or affect sharing, thereby diminishing the importance of a more global observation. The first aim of the present work was consequently to observe the quality of family interactions by extending the method applied in the study by Gueron-Sela et al, ${ }^{90}$ using all the LTP variables for the purpose of further elucidating the impact of family interactions on the child's development. We thus applied the LTP to a sample of families with children born preterm, comparing the results with those obtained in a group of families with children born at term. In this comparison, we expected to find differences in some variables of the LTP, specifically in child involvement and parental capacities in engaging the child during interactions. Given the fact that these variables could counterbalance each other, we also anticipated to find no differences in terms of global quality of family interactions, as suggested by Gueron-Sela et al. ${ }^{90}$

The second aim of the present study was to investigate in the preterm group the parents' self-perception of their parental empowerment, level of parenting stress, and perceived social support, in order to observe the influence of these constructs on the quality of family interactions. We hypothesized a strong association between low quality of family interactions and low parental empowerment, high level of parenting stress, and low level of perceived social support.

As observed in a previous study, ${ }^{91}$ which emphasized the importance of child factors, child's interactive abilities may contribute to an improvement of family interaction quality. In this study, we set out to observe the influence of the child's temperament on the perception of parenting stress and family empowerment and consequently on the quality of family interactions. We hypothesized that difficult temperament qualities were expected to be correlated with low quality of family interactions, low parental empowerment, and high level of parenting stress. As emerged from previous studies, ${ }^{92,93}$ the preterm group was found to be more affected by the quality of early caregiving than the normative group, suggesting that both researchers and clinicians should exploit the opportunities afforded by the observation of family interactions in cases of prematurity. ${ }^{90}$ Our study aimed to contribute to filling this gap by sketching some pictures of the dynamics involved.

\section{Materials and methods Participants and procedures}

The total sample consisted of 52 children with their families. The preterm group comprised 26 children (mean 22.3 months, SD 12.17). Families were recruited from two Italian organizations that offer support and intervention for preterm children and their families: a private Onlus association, Pulcino, and the Neurorehabilitation Service, forming part of the Unit for Children, Adolescents, and Families of the Public Health Service Unità Locale Socio Sanitaria (ULSS) in Padua. Families attending the Neurorehabilitation Service were recruited by a child neuropsychiatrist, who explained the purpose of the project and placed them in contact with the people responsible for this research project. Families in Pulcino were recruited by the association, which explained the purpose of the project, and (subject to family consent) placed them in contact with the people responsible. The LTP procedure and test battery were administered at the Unit for Children, Adolescents, and Families for all families.

All parents taking part in the project signed informed consent for the study, which was approved by the ethical committee of the ULSS 16 of Padua (CEP 204 SC). The control group employed in this study was part of a longitudinal study on the development of family interactions. ${ }^{94}$ This project involved a hundred couples who had spontaneously conceived their first child and were followed up from the seventh month of pregnancy until their child was 48 months old. A group of 26 
children (mean 22.2 months, SD 14.97) and their families was drawn from this sample, to match the preterm group in terms of the child's age and sex and the parents' ages.

The LTP procedure ${ }^{89}$ was administered to the two groups of families to assess the quality of their family interactions. The group with preterm children was also administered the following questionnaires: the Questionari Italiani del Temperamento, ${ }^{95}$ the Family Empowerment Scale (FES), ${ }^{96}$ the PSI-SF, ${ }^{37}$ and the Multidimensional Scale of Perceived Social Support. ${ }^{97}$ Table 1 shows the characteristics of the two groups.

\section{Materials}

The following materials were selected from the literature to answer to our specific research questions.

\section{Lausanne Trilogue Play}

The LTP is a specific semistandardized procedure that observes the quality of parent-child interactions in a play observational situation. ${ }^{89}$ The play is divided into four parts corresponding to the four possible interactive configurations. In part 1, one of the two parents interacts with the child while the other stays simply present (configuration $2+1$ ). In part 2 , the parents' roles are reversed (configuration $2+1$ ). In part 3 , both parents interact together with the child (configuration 3 ). In part 4 , the parents talk together while the child remains an observer (configuration 2+1). Three chairs forming an

Table I Descriptive analysis of the groups of families with children born preterm and at term

\begin{tabular}{lllll}
\hline & $\mathbf{n}$ & $\%$ & Mean & SD \\
\hline $\begin{array}{l}\text { Preterm } \\
\text { Sex }\end{array}$ & & & & \\
$\quad$ Males & 17 & 65.4 & & \\
$\quad$ Females & 9 & 34.6 & & \\
Degree of prematurity & & & & \\
$\quad$ Preterm & 6 & 23.1 & & \\
$\quad$ Very preterm & 11 & 42.3 & & \\
$\quad$ Extremely preterm & 9 & 34.6 & \\
Birth weight & & & \\
$\quad$ Normal & 2 & 7.7 & & \\
$\quad$ Low & 5 & 19.2 & & \\
$\quad$ Very low & 9 & 34.6 & & \\
$\quad$ Extremely low & 10 & 38.5 & & \\
Disability & & & & \\
$\quad$ Yes & 7 & 26.9 & & \\
$\quad$ No & 19 & 73.1 & & \\
Age (months) & & & 22.3 & \\
At term & & & & \\
Sex & & & & \\
$\quad$ Males & 17 & 65.4 & \\
$\quad$ Females & 9 & 34.6 & \\
Age (months) & & & \\
\hline
\end{tabular}

equilateral triangle compose the specific setting (a high chair is adapted to the age of the child).

The procedure was coded according to the Family Alliance Assessment Scale 4.0 (unpublished manual, Centre d'Etude de la Famille [CEF] 2006). Scores range from 1 (inappropriate) to 3 (appropriate) for 10 variables, according to the frequency and duration of interactive behaviors. Scores were attributed to each variable for each of the four separate parts and also computed together (total range 60-180). Two trained independent judges coded the videotapes of this research, achieving a Cohen's $\kappa$-value of 0.9 .

\section{Questionari Italiani del Temperamento}

This is an Italian self-report questionnaire that aims to assess a child's temperament in four age ranges. ${ }^{95}$ For the present study, the questionnaires for children aged 1-12 months, 13-36 months, and 3-6 years were used, which consist of 55,56 , and 60 items, respectively, and are divided into six subscales: social orientation, inhibition to novelty, motor control activity, attention, positive emotionality, and negative emotionality. The questionnaire can be answered by parents (even with a low-medium formal education), educators/ teachers, or anyone taking care of the child and spending time with them every day, so that the respondent can think about the child in three different contexts (child with others, child playing alone, child dealing with novelty or while performing an activity or a task). Answers are given on a Likert scale ranging from "almost never" (1) to "almost always" (6).

\section{Family Empowerment Scale}

The FES is a brief questionnaire designed to assess family members' perceptions of empowerment. ${ }^{96}$ The 34 FES items tap into two dimensions of family empowerment: level of empowerment (family, service system, community/political) and how empowerment is expressed (attitudes, knowledge, behavior). Given the focus of the study, only the family subscale (12 items) that refers to the parents' management of everyday situations was used. Answers are given on a Likert scale and range from "never" (1) to "very often" (5). Total scores range from 12 to 60 , and there is no cutoff.

\section{Parenting Stress Index - Short Form}

The PSI-SF ${ }^{37}$ (Italian version) ${ }^{98}$ is a self-report questionnaire that aims to identify stressful parent-child relational systems at risk of leading to dysfunctional behavior on the part of the parent or child. The short form (the only one validated in Italy) comprises 36 items scored on a Likert scale from 1 (strongly agree) to 5 (strongly disagree). The items are divided into three scales: parental stress, parent-child 
dysfunctional interaction, and difficult child. The first scale concerns parent's feelings of being trapped in the parenting role, the second measures the nature of the interaction between the parent and the child, and the third assesses parents' perceptions of their children.

\section{Multidimensional Scale of Perceived Social Support}

The Multidimensional Scale of Perceived Social Support ${ }^{97}$ (Italian version $^{99}$ is a brief self-report scale composed of 12 items that measure three areas: perceived social support from family, from friends, and from significant others. Answers can be scored on a Likert scale from 1 (strongly agree) to 7 (strongly disagree). The instrument has no cutoff. The maximum score is 84 and the minimum is 12 .

\section{Results}

\section{Preliminary analyses}

As shown in Table 1, our sample of preterm children included 7 children with and 19 without disabilities. Before comparing the quality of family interactions between the preterm group and the group with children born at term, an independentsamples $t$-test was run between the two preterm subgroups to see whether the presence of disabilities influenced the quality of family interactions. No differences emerged in their total LTP scores $\left(t_{24}=-0.211, P=0.835\right)$.

A $t$-test was also run on the same two subgroups of parents of preterm children to check whether the presence of disabilities influenced their perception of parental empowerment and parenting stress. No differences came to light: PSI total score mother $\left(t_{21}=1.97, P=0.062\right)$, PSI total score father $\left(t_{21}=0.712, P=0.484\right)$, FES mother $\left(t_{21}=-0.734\right.$; $P=0.471)$, FES father $\left(t_{21}=-1.647, P=0.115\right)$. As a result of these preliminary analyses, the preterm group was judged to be homogeneous.

\section{Family interactions}

Our first aim was to observe the quality of family interactions in a group of families with preterm children compared to a control group of families with infants born at term, exploring the trend of the four possible interactive configurations. Given the homogeneity of the preterm group, a $t$-test was performed to compare the quality of family interactions between the preterm group and the full-term group, results are given in Table 2.

A multivariate analysis of variance was performed between the variables of LTP, showing a significant difference between the preterm group and controls $\left(F_{9,42}=8.395\right.$, Wilks's $\lambda=0.357 ; P<0.001)$. Given the significant difference between the two groups, the trend of the four parts characterizing the preterm group was analyzed through a repeatedmeasures analysis of variance, with the four LTP parts as the within-subject factor. Results showed a significant part effect $\left(F_{3.75}=8.54, P<001\right)$ for the preterm group. A Bonferroni post hoc analysis confirmed that the score of the fourth part (Figure 1) was significantly lower than the score of the second $(P=0.008)$ and third $(P=0.001)$ parts.

\section{Influence of parental empowerment, child temperament, parenting stress, and perceived social support on the quality of family interactions}

The second aim of our study was to examine the relationship between the quality of family interactions and parental empowerment, child's temperament, parenting stress, and

Table 2 Comparison of preterm group with control group (infants born at term)

\begin{tabular}{|c|c|c|c|c|c|c|c|}
\hline \multirow[t]{2}{*}{ Significant LTP scales } & \multicolumn{2}{|c|}{$\begin{array}{l}\text { Preterm group } \\
(n=26)\end{array}$} & \multicolumn{2}{|c|}{$\begin{array}{l}\text { Control group } \\
(n=26)\end{array}$} & \multirow[t]{2}{*}{$t$} & \multirow[t]{2}{*}{$d f$} & \multirow[t]{2}{*}{$P$-value } \\
\hline & $\mu$ & $\delta$ & $\mu$ & $\delta$ & & & \\
\hline LTP total score & 87.27 & 11.007 & 99.88 & 6.89 & -4.954 & 41.981 & $<0.001$ \\
\hline Part I & 21.27 & 4.21 & 25.69 & 1.32 & -5.112 & 29.866 & $<0.001$ \\
\hline Part 2 & 23.12 & 3.398 & 25.69 & 2.589 & -3.076 & 50 & 0.003 \\
\hline Part 4 & 19.42 & 4.474 & 23.5 & 3.24 & -3.763 & 50 & $<0.001$ \\
\hline Postures and gazes & 8.77 & 2.065 & 11.04 & 0.999 & -5.044 & 36.098 & $<0.001$ \\
\hline Role implication & 9.85 & 1.759 & 10.85 & 1.19 & -2.401 & 43.909 & 0.021 \\
\hline Parental scaffolding & 9.92 & 1.495 & II & 1.47 & -2.62 & 50 & 0.012 \\
\hline Infant's involvement & 10.27 & 1.43 & $1 \mathrm{I} .42$ & 0.902 & -3.48 & 42.18 & 0.001 \\
\hline Coconstruction & 8.42 & 2.176 & 10.73 & 1.185 & -4.749 & 38.635 & $<0.001$ \\
\hline Validation & 10.54 & 1.24 & II.77 & 0.43 & -4.781 & 30.915 & $<0.001$ \\
\hline Family warmth & 8.42 & 2.157 & 11.46 & 1.104 & -6.393 & 37.251 & $<0.001$ \\
\hline
\end{tabular}

Abbreviation: LTP, Lausanne Trilogue Play. 


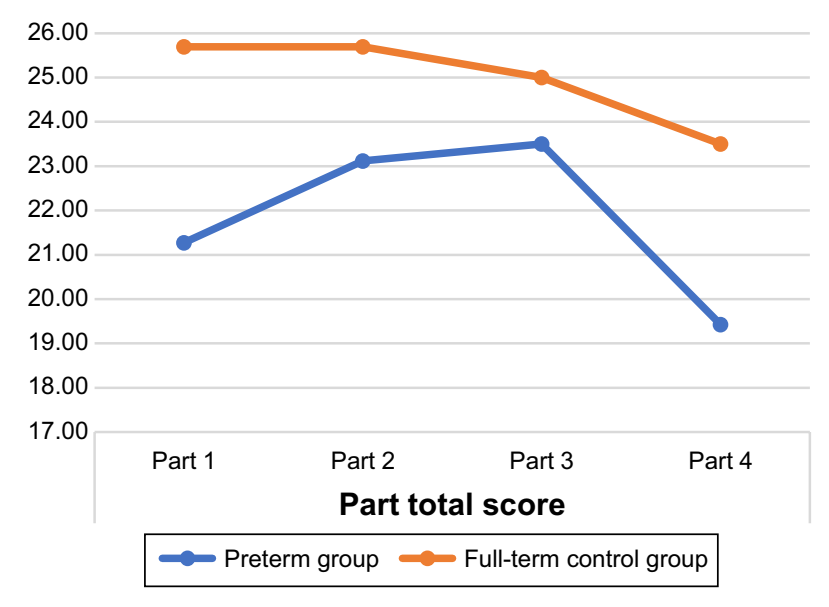

Figure I Trend of the LTP parts in the preterm and at term groups. Abbreviation: LTP, Lausanne Trialogue Play.

perceived social support in the group of families with children born preterm. Table 3 presents a descriptive analysis of all the instruments used for this purpose.

Given the homogeneity of the preterm group, even with regard to parental empowerment, child's temperament, parenting stress, and perceived social support, Pearson's correlations were run to identify the relationship between the aforementioned constructs and the quality of family interactions. Table 4 shows the positive correlations. In the preterm group, the relationship between the perception of parental empowerment, the child's temperament, parenting stress, and perceived social support was also considered. Table 5 shows the corresponding Pearson's correlations.

\section{Discussion}

The general goal of this work was to observe the quality of family interactions in a sample of families with children born preterm and to explore possible differences compared to a normative population. Our results showed a significant difference between these two groups in terms of the quality of family interactions. The control group (families with children born at term) scored significantly higher in the first, second, and fourth parts of the LTP and in the total score. Differences emerged from the sum of the LTP variables - postures and gazes, role implication, parental scaffolding, infant's involvement, co-construction, validation, and family warmth confirming a low performance of the preterm group.

Our data were not consistent with the results of GueronSela et al,${ }^{90}$ who found no LTP score differences between families with children born preterm and with children born at term when the infant was 6 months old (corrected age). Our hypothesis regarding this incongruity is that it was probably due to the fact that the peculiarities of parental interactions with preterm children start to emerge in the second half of the child's first year of life, when the child's environment becomes increasingly complex and demanding. ${ }^{70,74}$ In other words, our research could be related to this subsequent phase, given the higher mean age of our group.

An important result, however, which is worth emphasizing, concerns an aspect that did not emerge as differing significantly in the comparison between the preterm and full-term groups, ie, the total score for the third part of the procedure (when all three parties should interact actively and mutually), and the sum of the variables "inclusion of partners" and "support and cooperation". It means that regardless of the aforementioned difficulties, parents of preterm children participate actively and succeed in supporting and cooperating in this triadic interactive configuration so that the interaction is conducted fluidly. The quality of the coparenting alliance does not seem to be negatively influenced by prematurity, suggesting that despite the deficit emerging on a dyadic level regarding both the parent-child relationship and the marital couple, this could be a fundamental resource of these families. This finding also goes to show that even with very young children, there is not a better functioning of the dyadic interaction compared to the triadic one, and/or there is no single active parent, be it mother or father, with whom the child develops an elective functioning. The "best performance" seems to coincide with the situation where both partners are active and cooperative, and probably after a warming period represented by the first two parts.

Taking into account the trend of the four parts of the LTP, it seems that some deficiencies arising at the start of the interactive exchange gradually dissipate, coming to reach the same quality as in the normative families in the third part and subsequently deteriorating again in the fourth and last part, dedicated to the parents' interactive exchange. It was apparent that parents did not enrich the dialog in the fourth part by considering the stimulus offered by the other partner. They seemed to have a strong tendency to remain focused on the child, as if to underline their greater attention to the child's activity. In other words, they struggled to leave the child "alone in their presence".

Our results compare families with preterm children and families with children born at term pointing out difficulties in creating the optimal context for fostering emotional exchanges during interactions through eye contact and posture sharing. There was in fact some evidence of rupture of affect circularity: affect was often shared only on the dyadic level. During dyadic interactions, the parent in the active role 
Table 3 Descriptive analysis of QUIT, PSI-SF, FES, MSPSS, and LTP results

\begin{tabular}{|c|c|c|c|c|}
\hline Instrument & Scales & Sample size & Mean score & SD \\
\hline & & Child's age subgrc & & \\
\hline \multirow[t]{19}{*}{ QUIT } & Social orientation & $\mathrm{I}-12$ months $(5)$ & 4.45 & 0.58 \\
\hline & & I2-36 months (I7) & 4.02 & 0.79 \\
\hline & & $3-6$ years $(4)$ & 4.33 & 0.49 \\
\hline & Inhibition to novelty & $\mathrm{I}-12$ months (5) & 2.35 & 0.69 \\
\hline & & I2-36 months (I7) & 2.45 & 0.67 \\
\hline & & $3-6$ years $(4)$ & 2.71 & 0.34 \\
\hline & Motor control activity & I-12 months (5) & 2.89 & 0.93 \\
\hline & & $12-36$ months (17) & 3.59 & 0.52 \\
\hline & & $3-6$ years (4) & 3.81 & 0.81 \\
\hline & Positive emotionality & $\mathrm{I}-12$ months (5) & 4.93 & 0.7 \\
\hline & & I2-36 months (I7) & 4.86 & 0.99 \\
\hline & & $3-6$ years $(4)$ & 4.19 & 0.51 \\
\hline & Negative emotionality & $\mathrm{I}-12$ months (5) & 2.96 & 1.08 \\
\hline & & $12-36$ months $(17)$ & 2.63 & 0.9 \\
\hline & & $3-6$ years $(4)$ & 3.06 & 1.04 \\
\hline & Attention & I-12 months (5) & 4.43 & 0.62 \\
\hline & & I2-36 months (I7) & 4.2 & 0.82 \\
\hline & & $3-6$ years $(4)$ & 4.03 & 0.47 \\
\hline & & Parents & & \\
\hline \multirow[t]{10}{*}{ PSI-SF } & PD & Mothers (25) & 25.73 & 7.242 \\
\hline & & Fathers (25) & 24.77 & 7.906 \\
\hline & P-CDI & Mothers (25) & 19 & 5.692 \\
\hline & & Fathers (25) & 19.35 & 4.39 \\
\hline & DC & Mothers (25) & 22.65 & 5.513 \\
\hline & & Fathers (25) & 21.81 & 5.004 \\
\hline & Total stress & Mothers (25) & 67.38 & 15.784 \\
\hline & & Fathers (25) & 66 & 14.805 \\
\hline & Defensive responding & Mothers (25) & 15.15 & 4.259 \\
\hline & & Fathers (25) & 14.54 & 5.346 \\
\hline \multirow[t]{2}{*}{ FES } & Total score & Mothers (25) & 46.54 & 3.669 \\
\hline & & Fathers (25) & 45.42 & 7.083 \\
\hline \multirow[t]{9}{*}{ MSPSS } & Total score & Mothers (20) & 68.6 & 11.062 \\
\hline & & Fathers (20) & 67.75 & 13.719 \\
\hline & Family & Mothers (20) & 22.8 & 6.084 \\
\hline & & Fathers (20) & 23.9 & 5.119 \\
\hline & Friends & Mothers (20) & 21 & 5.037 \\
\hline & & Fathers (20) & 21.05 & 4.979 \\
\hline & Significant others & Mothers (20) & 24.3 & 3.629 \\
\hline & & Fathers (20) & 22.8 & 5.89 \\
\hline & & Families & & \\
\hline \multirow[t]{14}{*}{ LTP } & LTP total score & 26 & 87.27 & 11.007 \\
\hline & Part I & 26 & 21.27 & 4.21 \\
\hline & Part 2 & 26 & 23.12 & 3.398 \\
\hline & Part 3 & 26 & 23.5 & 3.603 \\
\hline & Part 4 & 26 & 19.42 & 4.474 \\
\hline & Postures and gazes, sum & 26 & 8.77 & 2.065 \\
\hline & Inclusion of partners, sum & 26 & $\mathrm{II}$ & 1.265 \\
\hline & Support and cooperation, sum & 26 & 10.08 & 1.853 \\
\hline & Role implication, sum & 26 & 9.85 & $\mathrm{I} .759$ \\
\hline & Parental scaffolding, sum & 26 & 9.92 & 1.495 \\
\hline & Infant's involvement, sum & 26 & 10.27 & 1.43 \\
\hline & Coconstruction, sum & 26 & 8.42 & 2.176 \\
\hline & Validation, sum & 26 & 10.54 & 1.24 \\
\hline & Family warmth, sum & 26 & 8.42 & 2.157 \\
\hline
\end{tabular}

Abbreviations: QUIT, Questionari Italiani del Temperamento; PSI-SF, Parenting Stress Index - Short Form; FES, Family Empowerment Scale; MSPSS, Multidimensional Scale of Perceived Social Support; LTP, Lausanne Trilogue Play; PD, parental distress; P-CDI, parent-child dysfunctional interaction; DC, difficult child. 
Table 4 Correlations between LTP and PSI-SF, FES, and MSPSS

\begin{tabular}{lllll}
\hline Instrument & $\begin{array}{l}\text { Respect for } \\
\text { task's structure } \\
\text { and time frame }\end{array}$ & $\begin{array}{l}\text { Parental } \\
\text { scaffolding }\end{array}$ & Self-regulation & $\begin{array}{l}\text { Conflicts and } \\
\text { disruptive } \\
\text { interferences }\end{array}$ \\
\hline Total stress & $\begin{array}{l}-0.388^{*} \text { mother } \\
-0.44^{*} \text { mother }\end{array}$ & $\begin{array}{l}\text { Infant } \\
\text { involvement }\end{array}$ \\
PSI PD & & $0.409^{*}$ mother & $-0.427^{*}$ father & \\
PSI DC & & $-0.393^{*}$ & $-0.397^{*}$ father & $0.404^{*}$ father \\
PSI P-CDI & & $-0.56^{*}$ & & $-0.415^{*}$ father \\
FES mother & & & \\
FES father & & &
\end{tabular}

Note: $* P<0.05$.

Abbreviations: LTP, Lausanne Trilogue Play; PSI-SF, Parenting Stress Index - Short Form; FES, Family Empowerment Scale; MSPSS, Multidimensional Scale of Perceived Social Support; PD, parental distress; DC, difficult child; P-CDI, parent-child dysfunctional interaction.

seems to use several strategies to engage the child, penalizing eye contact and affect circularity with the third (the other parent), thus influencing family warmth. In this regard, the low score on the variable "role implication" showed that parents had difficulty remaining in the role of the observer, and tended to show signs of wanting to interact with the baby to see their active presence acknowledged.

Lower scores for "parental scaffolding" were awarded mainly because parents gave contradictory signals to the child during the fourth part of the LTP, sometimes taking the child back to their role as an observer, sometimes stimulating them directly. In the other parts of the procedure, parents (and especially mothers) tended to be hypostimulating, a finding not entirely consistent with other reports in literature..$^{60,71,81}$ This aspect sometimes comes up together with the exclusive use of the verbal channel. ${ }^{71}$ During the play, the emotions expressed and shared in the preterm group seemed to be mainly neutral. These families had been exposed from the start to their child's lengthy hospitalization and fragility. They had faced, more or less consciously, the risk of loss, and thus, they could may have found it harder to let themselves go in a free flow of affections and relations. ${ }^{100}$

We know from the literature that parents of preterm children (and mothers in particular) struggle more in organizing their mental representations of their child and of themselves, ${ }^{101}$ partly due to the emotional issues raised by prematurity ${ }^{102,103}$ and partly due to the child's characteristics, ${ }^{104}$ and this would prompt a greater "presentification" on the parent's part. Research highlights that parental scaffolding also seems to be somehow impaired by the difficulty of interpreting the preterm baby's communicative clues, which are often far from clear. ${ }^{76,77}$

Table 5 Pearson's correlations between PSI-SF and QUIT, FES, and MSPSS

\begin{tabular}{|c|c|c|c|c|c|c|c|c|}
\hline & \multicolumn{4}{|c|}{ PSI-SF mother } & \multicolumn{4}{|c|}{ PSI-SF father } \\
\hline & PD & P-CDI & DC & Total & PD & P-CDI & DC & Total \\
\hline \multicolumn{9}{|l|}{ QUIT } \\
\hline Attention & $-0.581 * *$ & & & $-0.5 * *$ & $-0.405^{*}$ & $-0.425^{*}$ & & $-0.442 *$ \\
\hline \multicolumn{9}{|l|}{ FES } \\
\hline FES mother & & $-0.517 * *$ & $-0.467^{*}$ & $-0.554 * *$ & & & & \\
\hline FES father & $-0.402 *$ & & & & $-0.557^{* *}$ & & $-0.547^{* *}$ & $-0.587 * *$ \\
\hline \multicolumn{9}{|l|}{ MSPSS mother } \\
\hline MSPSS total score & $-0.497 *$ & $-0.625 * *$ & $-0.629 * *$ & $-0.688 * *$ & & & & \\
\hline MSPSS family & & $-0.732 * *$ & & $-0.594 * *$ & & & & \\
\hline MSPSS significant others & $-0.498^{*}$ & & $-0.476 *$ & $-0.502 *$ & & & & \\
\hline \multicolumn{9}{|l|}{ MSPSS father } \\
\hline MSPSS total score & & $-0.479 *$ & & $-0.526^{*}$ & $-0.745^{* *}$ & & $-0.446^{*}$ & $-0.63 I^{* *}$ \\
\hline MSPSS family & & & & & $-0.73 * *$ & & & $-0.558^{*}$ \\
\hline MSPSS friends & & $-0.549 *$ & & $-0.516 *$ & $-0.494 *$ & & & $-0.495^{*}$ \\
\hline MSPSS significant others & & & $-0.464 *$ & $-0.487^{*}$ & $-0.684 * *$ & & & $-0.566 * *$ \\
\hline
\end{tabular}

Notes: $* P<0.05 ; * *<0.01$.

Abbreviations: PSI-SF, Parenting Stress Index - Short Form; QUIT, Questionari Italiani del Temperamento; FES, Family Empowerment Scale; MSPSS, Multidimensional Scale of Perceived Social Support; PD, parental distress; P-CDI, parent-child dysfunctional interaction; DC, difficult child. 
Parents' validation of the child's emotional experience is not stable. They alternate moments of connectivity with child emotions and moments characterized by low sensitivity. ${ }^{84}$ This aspect could also be seen as a difficulty in interpreting the baby's uncertain communicative clues, which are not always clear to their parents. ${ }^{76,77}$ As for the child's involvement, in some cases children restricted themselves to observing the parents, following the activities with their gaze rather than taking an active part, ${ }^{18}$ or preferring to play alone. From the triadic and interactive perspective, although our observations stemmed from a new and a different point of view, our study is in line with the literature, in which preterm children are showed to be more passive, ${ }^{60,61}$ less alert and focused, ${ }^{62,63}$ and less responsive. ${ }^{64,65}$

On the whole, families struggled with coconstructing activities, sharing and enriching them, even when the child displayed good levels of ability, communicative expression, and involvement. Our findings about coconstruction ability, are in line with the literature on the characteristics of preterm children, who reportedly establish less eye contact with their caregivers, ${ }^{67-69}$ display a lesser tendency for some types of behavior, such as gazing, which is commonly considered an important precursor of the first relational exchanges, and thus is an indicator of a greater difficulty in constructing primary intersubjectivity. ${ }^{18,59,69}$ It could also be said that given the child's developmental level, the parents' gaze allows a psychological existence for their child, but also the child's gaze allows a psychological existence for the parents. From a triadic perspective, right from the first interactions, the child is consequently able to contribute to the characteristics of the family's interactive dynamics. Overall, our results seem to confirm on the triadic level the difficulties already described in the literature during dyadic interactive exchanges in terms of eye contact with preterm children ${ }^{69}$ and the latter's expression of mainly neutral affection. ${ }^{18}$

It is probably particularly difficult for parents and their babies to direct and share attention on a common focus, and this could be due to the parents' failure to comply with the turn-taking rules, to an interaction rigidly structured by the parent, ${ }^{64}$ or to a primary deficit in their ability to share through postures and gazes. Parents seemed to find it difficult to connect with the preterm child's timing, as they tended to anticipate the duration of the child's activities.

Another focus of this study was to examine in families with preterm children the relationship between family interactions and parental empowerment, the child's temperament, parenting stress, and perceived social support. In light of the correlations emerged between maternal parenting stress with the sum of the two variables "parental scaffolding" and "respect for the task's structure and time frame", couples in which mothers were more stressed seemed to be able to provide appropriate stimulation, probably serving the purpose of offering a frame and a stimulation that secured the child's engagement and interest, and thereby countering their negative perceptions of the child who had become a source of stress (a low level of attention in particular). The mother is not only less stressed, the more the child proves to be attentive, but she also feels more competent as a parent. This goes to show that it is feasible for these mothers to synchronize/connect with their child, even though it seems to be more stressful and laborious. On the other hand, it may be that struggling to involve their child in the interactive play could make mothers experience this situation as a performance, which would guarantee an appropriate stimulation for the child, but at the same time would also be a source of stress for the mother, giving them a weaker perception of competence.

In agreement with the literature, ${ }^{38}$ parenting stress seemed to be more severe in parents with preterm children. While the mother's stress seems to relate to structuring and characterizing aspects of her interactions with the child, the father's stress is clearly related to specific characteristics of the child. Preterm infants show little outward signs of their communicative skills, and it seems difficult to engage them. A child who has difficulty in regulating themselves also generates further stress on the father, who experiences his interactions with the child as stressful. This makes it more stressful for fathers to relate with the negative emotions of their children.

No correlations have been found between child's temperament with family interactions, parental empowerment and perceived social support. What emerges from our result is a significant correlation between the variable "attention" and maternal and paternal parenting stress, confirming that parenting stress increases with the decrease of child attention.

Finally, our study confirmed the importance of social support for parents, ${ }^{54,55}$ which emerged from correlations with parenting stress for both mothers and fathers. For fathers, social support (especially the support perceived as coming from their family) had a stronger influence on the stress they experienced as a function of their parental role and on their parental empowerment. For mothers, it mainly affected their experience of a dysfunctional interaction with their child or their perception of the child as being difficult to manage. The mother's stress also correlated with the father's perception of social support, but not vice versa. We hypothesize that a father's stronger perception of social support could serve as a protective factor for the mother-child dyad too, because its influence on paternal stress would help to guarantee the protective function of the father's role. 


\section{Conclusion}

Our research was conducted in a field that has been little studied so far before: observation of the quality of triadic interactions in families with children born preterm. This preliminary work highlights some differences in the interactive exchanges of families with preterm children, both in creating the space appropriate for promoting exchange, involvement, and participation in the child and in aspects relating to emotionality, which does not reveal the positivity to be expected in a playful situation (as happens for families with children born at term). Our most important finding, however, indicates that faced with the difficulties that appear when dyads are expected to interact actively, when all family members should interact mutually, the families with preterm children succeed in contributing to completion of the task, generating pleasant sharing moments. This result, along with the finding regarding parents' support and cooperation, is an indication of the quality of the coparenting couple and represents the fundamental resource identified in these families. The LTP procedure aims to bring to light a family's limits, but even more its resources, so that the intervention can then be planned taking the latter into account. ${ }^{105,106}$ Parents' capacity of emotional and interactive coordination can be reinforced to create a positive climate where affect can be authentically expressed and shared, and this could certainly be a protective factor, and when treatments are needed, a good basis for building a positive working alliance is finalized to caregiving experience improvement. ${ }^{107-109}$

The main limits of our research concern the sample size, which was not large enough to allow us the generalization of our results, and the use of self-report questionnaires. Our research group is thus expanding its collaborations with a view to increasing the sample size and consequently becoming able to identify the presence or any differences and peculiarities relating to the degree of prematurity and the child's birth weight. We are also planning a follow-up to monitor families involved in this study, not only to enrich our knowledge of their subsequent development but also to offer preventive support to the marital and coparenting couples.

\section{Disclosure}

The authors report no conflicts of interest in this work.

\section{References}

1. World Health Organization. WHO Recommendations on Interventions to Improve Preterm Birth Outcomes. Geneva, Switzerland: WHO; 2015.

2. Ministero della Salute. Nuovo rapporto CeDAP, analisi dell'evento nascita in Italia. 2012. Available from: http://www.salute.gov.it/portale/ news/p3_2_1_1_1.jsp?lingua=italiano\&menu=notizie $\&$ p=dalministero $\& \mathrm{id}=459$. Accessed May 30, 2017.
3. Spittle AJ, Walsh J, Olsen JE, et al. Neurobehaviour and neurological development in the first month after birth for infants born between 32-42 weeks' gestation. Early Hum Dev. 2016;96:7-14.

4. Mento G, Bisiacchi PS. Sviluppo neuro-cognitivo in nati pretermine:la prospettiva delle Neuroscienze cognitive dello sviluppo. Psicol Clin Sviluppo. 2013;17:27-44.

5. Johnson S, Marlow N. Preterm birth and childhood psychiatric disorders Pediatr Res. 2011;69:11R-18R.

6. Montagna A, Nosarti C. Socio-emotional development following very preterm birth: pathways to psychopathology. Front Psychol. 2016;7:80.

7. Bhutta AT, Cleves MA, Casey PH, Cradock MM, Anand KJ. Cognitive and behavioral outcomes of school-aged children who were born preterm. JAMA. 2002;288:728-737.

8. Saigal S, Doyle LW. An overview of mortality and sequelae of preterm birth from infancy to adulthood. Lancet. 2008;371:261-269.

9. Hoff B, Hansen BM, Munck H, Mortensen EL. Behavioral and social development of children born extremely premature: 5 -year follow-up. Scand J Psychol. 2004;45:285-292.

10. Wolke D. Psychological development of prematurely born children. Arch Dis Child. 1998;78:567-570.

11. Coletti MF, Caravale B, Gasparini C, Franco F, Campi F, Dotta A. One-year neurodevelopmental outcome of very and late preterm infants: risk factors and correlation with maternal stress. Infant Behav Dev. 2015;39:11-20.

12. Grunau R, Whitfield MF, Petrie-Thomas J, et al. Neonatal pain, parenting stress and interaction, in relation to cognitive and motor development at 8 and 18 months in preterm infants. Pain. 2009;143:138-146.

13. Böhm B, Smedler AC, Forssberg H. Impulse control, working memory and other executive functions in preterm children when starting school. Acta Paediatr. 2004;93:1363-1371.

14. Marlow N, Hennessy EM, Bracewell MA, Wolke D. Motor and executive function at 6 years of age after extremely preterm birth. Pediatrics. 2007;120:793-804.

15. Nosarti C, Giouroukou E, Micali N, Rifkin L, Morris RG, Murray RM Impaired executive functioning in young adults born very preterm. J Int Neuropsychol Soc. 2007;13:571-581.

16. Mulder H, Pitchford NJ, Hagger MS. Development of executive function and attention in preterm children: a systematic review. Dev Neuropsychol. 2009;34:393-421.

17. Sansavini A, Pentimonti J, Justice L, et al. Language, motor and cognitive development of extremely preterm children: modeling individual growth trajectories over the first three years of life. J Commun Disord. 2014;49:55-68

18. Sansavini A, Guarini A, Savini S, et al. Longitudinal trajectories of gestural and linguistic abilities in very preterm infants in the second year of life. Neuropsychologia. 2011;49:3677-3688.

19. Stene-Larsen K, Brandlistuen RE, Lang AM, Landolt MA, Latal B, Vollrath ME. Communication impairments in early term and late preterm children: a prospective cohort study following children to age 36 months. J Pediatr. 2014;165:1123-1128.

20. Barre N, Morgan A, Doyle LW, Anderson PJ. Language abilities in children who were very preterm and/or very low birth weight: a metaanalysis. J Pediatr. 2011;158:766-774.

21. de Kieviet JF, Piek JP, Aarnoudse-Moens CS, Oosterlaan J. Motor development in very preterm and very low-birth-weight children from birth to adolescence: a meta-analysis. JAMA. 2009;302:2235-2242.

22. Arpi E, Ferrari F. Preterm birth and behavior problems in infants and preschool-age children: a review of the recent literature. Dev Med Child Neurol. 2013;55:788-796

23. Perricone G, Morales MR. The temperament of preterm infant in preschool age. Ital J Pediatr. 2011;37:4.

24. Ghorbani M, Dolatian M, Shams J, Alavi-Majd H, Tavakolian S. Factors associated with posttraumatic stress disorder and its coping styles in parents of preterm and full-term infants. Glob J Health Sci. 2014;6: $65-73$.

25. Holditch-Davis D, Schwartz T, Black B, Scher M. Correlates of motherpremature infant interactions. Res Nurs Health. 2007;30:333-346. 
26. Davis L, Edwards H, Mohay H, Wollin J. The impact of very premature birth on the psychological health of mothers. Early Hum Dev. 2003;73:61-70.

27. Wu C, Hung C, Chang Y. Predictors of health status in mothers of premature infants with implications for clinical practice and future research. Worldviews Evid Based Nurs. 2015;12:217-227.

28. Zanardo V, Freato F, Zacchello F. Maternal anxiety upon NICU discharge of high-risk infants. J Reprod Infant Psycol. 2003;21:69-75.

29. Voegtline KM, Stifter CA. Late-preterm birth, maternal symptomatology, and infant negativity. Infant Behav Dev. 2010;33:545-554.

30. Shaw RJ, Lilo EA, Storfer-Isser A, et al. Screening for symptoms of postpartum traumatic stress in a sample of mothers with preterm infants. Issues Ment Health Nurs. 2014;35:198-206.

31. Miles MS, Holditch-Davis D, Schwartz TA, Scher MD. Depressive symptoms in mothers of prematurely born infants. J Dev Behav Pediatr. 2007;28:36-44.

32. Silverstein M, Feinberg E, Young R, Sauder S. Maternal depression, perceptions of children's social aptitude and reported activity restriction among former very low birth weight infants. Arch Dis Child. 2010; 95:521-525

33. Vigod SN, Villegas L, Dennis CL, Ross LE. Prevalence and risk factors for postpartum depression among women with preterm and low-birthweight infants: a systematic review. BJOG. 2010;117:540-550.

34. Helle N, Barkmann C, Ehrhardt S, von der Wense A, Nestoriuc Y, Bindt C. Postpartum anxiety and adjustment disorders in parents of infants with very low birth weight: cross-sectional results from a controlled multicentre cohort study. J Affect Disord. 2016;194:128-134.

35. Pierrehumbert B, Nicole A, Muller-Nix C, Forcada-Guex M, Ansermet F. Parental post-traumatic reactions after premature birth: implications for sleeping and eating problems in the infant. Arch Dis Child Fetal Neonatal Ed. 2003;88:F400-F404.

36. Shaw RJ, Bernard RS, Deblois T, Ikuta LM, Ginzburg K, Koopman C. The relationship between acute stress disorder and post-traumatic stress disorder in the neonatal intensive care unit. Psychosomatics. 2009;50:131-137.

37. Abidin RR. Parenting Stress Index-Short Form. Charlottesville, VA: Pediatric Psychology Press; 1990.

38. Gray PH, Edwards DM, O'Callaghan MJ, Cuskelly M, Gibbons K. Parenting stress in mothers of very preterm infants: influence of development, temperament and maternal depression. Early Hum Dev. 2013; 89:625-629.

39. Olafsen KS, Kaaresen PI, Handegård BH, Ulvund SE, Dahl LB, Rønning JA. Maternal ratings of infant regulatory competence from 6 to 12 months: influence of perceived stress, birth-weight, and intervention - a randomized controlled trial. Infant Behav Dev. 2008; 31:408-421.

40. Beck CT. The effects of postpartum depression on maternal-infant interaction: a meta-analysis. Nurs Res. 1995;44:298-305.

41. Field T. Postpartum depression effects on early interactions, parenting, and safety practices: a review. Infant Behav Dev. 2010;33:1-6.

42. Lovejoy MC, Graczyk PA, O’Hare E, Neuman G. Maternal depression and parenting behavior: a meta-analytic review. Clin Psychol Rev. 2000;20:561-592.

43. Stein A, Pearson RM, Goodman SH, et al. Effects of perinatal mental disorders on the fetus and child. Lancet. 2014;384:1800-1819.

44. Browne JV, Talmi A. Family-based intervention to enhance infantparent relationships in the neonatal intensive care unit. $J$ Pediatr Psychol. 2005;30:667-677.

45. Sameroff AJ, Fiese BH. Transactional regulation: the development ecology of early intervention. In: Shonkoff JP, Meisels SJ, editors. Handbook of Early Childhood Intervention. Cambridge: Cambridge University Press; 2000:135-159.

46. Cusson RM. Factors influencing language development in preterm infants. J Obstet Gynecol Neonatal Nurs. 2003;32:402-409.

47. Evans T, Whittingham K, Boyd R. What helps the mother of a preterm infant become securely attached, responsive and well-adjusted? Infant Behav Dev. 2012;35:1-11.
48. McManus BM, Poehlmann J. Parent-child interaction, maternal depressive symptoms and preterm infant cognitive function. Infant Behav Dev. 2012;35:489-498.

49. Santos H, Yang Q, Docherty SL, White-Traut R, Holditch-Davis D. Relationship of maternal psychological distress classes to later motherinfant interaction, home environment, and infant development in preterm infants. Res Nurs Health. 2016;39:175-186.

50. Montirosso R, Arrigoni F, Casini E, et al. Greater brain response to emotional expressions of their own children in mothers of preterm infants: an fMRI study. J Perinatol. 2017;37:716-722.

51. Holditch-Davis D, Cox MF, Miles MS, Belyea M. Mother-infant interactions of medically fragile infants and non-chronically ill premature infants. Res Nurs Health. 2003;26:300-311.

52. Cheng ER, Kotelchuck M, Gerstein ED, Taveras EM, PoehlmannTynan J. Postnatal depressive symptoms among mothers and fathers of infants born preterm: prevalence and impacts on children's early cognitive function. J Dev Behav Pediatr. 2016;37:33-42.

53. Weiss SJ, Chen JL. Factors influencing maternal mental health and family functioning during the low birthweight infant's first year of life. J Pediatr Nurs. 2002;17:114-125.

54. Ghorbani M, Dolatian M, Shams J, Alavi-Majd H. Anxiety, posttraumatic stress disorder and social supports among parents of premature and full-term infants. Iran Red Crescent Med J. 2014;16:e13461.

55. Singer LT, Davillier M, Bruening P, Hawkins S, Yamashita T. Social support, psychological distress, and parenting strains in mothers of very low birthweight infants. Fam Relat. 1996;45:343-350.

56. Decker KA, Miller WR, Buelow JM. Parent perceptions of family social supports in families with children with epilepsy. J Neurosci Nurs. 2016;48:336-341.

57. Wakimizu R, Yamaguchi K, Fujioka H. Family empowerment and quality of life of parents raising children with developmental disabilities in 78 Japanese families. Int J Nurs Sci. 2017;4:38-45.

58. Bozzette M. A review of research on premature infant-mother interaction. Newborn Infant Nurs Rev. 2007;7:49-55.

59. Korja R, Latva R, Lehtonen L. The effects of preterm birth on motherinfant interaction and attachment during the infant's first two years. Acta Obstet Gynecol Scand. 2012;91:164-173.

60. Muller-Nix C, Forcada-Guex M, Pierrehumbert B, Jaunin L, Borghini A, Ansermet F. Prematurity, maternal stress and mother-child interactions. Early Hum Dev. 2004;79:145-158.

61. Hughes MB, Shults J, Mcgrath J, Medoff-Cooper B. Temperament characteristics of premature infants in the first year of life. J Dev Behav Pediatr. 2002;23:430-435.

62. Hall RA, Hoffenkamp HN, Tooten A, Braeken J, Vingerhoets AJ, van Bakel HJ. The quality of parent-infant interaction in the first 2 years after full-term and preterm birth. Parent Sci Pract. 2015;15: 247-268.

63. Minde K, Perrotta M, Marton P. Maternal caretaking and play with full-term and premature infants. J Child Psychol Psychiatr. 1985; 26:231-244.

64. Reissland N, Stephenson T. Turn-taking in early vocal interaction: a comparison of premature and term infants' vocal interaction with their mothers. Child Care Health Dev. 1999;25:447-456.

65. Singer LT, Fulton S, Davillier MK, Salvator A, Baley JE. Effects of infant risk status and maternal psychological distress on maternalinfant interactions during the first year of life. J Dev Behav Pediatr. 2003;24:233-241.

66. Salerni N, Suttora C, D'Odorico L. A comparison of characteristics of early communication exchanges in mother-preterm and mother-fullterm infant dyads. First Lang. 2007;27:329-346.

67. Malatesta CZ, Grigoryev P, Lamb C, Albin M, Culver C. Emotion socialization and expressive development in preterm and full-term infants. Child Dev. 1986;57:316-330.

68. Harel H, Gordon I, Geva R, Feldman R. Gaze behaviors of preterm and full-term infants in nonsocial and social contexts of increasing dynamics: visual recognition, attention regulation, and gaze synchrony. Infancy. 2011;16:69-90. 
69. Tenuta F, Costabile A, Marcone R, Corchia C, Lombardi O. La comunicazione precoce madre-bambino: un confronto tra diadi con bambino nato a termine e bambino nato pretermine. Psicol Clin Sviluppo. 2008;12:357-378.

70. Crnic KA, Ragozin AS, Greenberg MT, Robinson MN, Basham RB. Social interaction and developmental competence of preterm and full-term infants during the first year of life. Child Dev. 1983;54: 1199-1210.

71. Schmücker G, Brisch KH, Köhntop B, et al. The influence of prematurity, maternal anxiety, and infants' neurobiological risk on mother-infant interactions. Infant Ment Health J. 2005;26:423-441.

72. Montirosso R, Borgatti R, Trojan S, Zanini R, Tronick E. A comparison of dyadic interactions and coping with still-face in healthy pre-term and full-term infants. Br J Dev Psychol. 2010;28:347-368.

73. De Schuymer L, De Groote I, Striano T, Stahl D, Roeyers H. Dyadic and triadic skills in preterm and full term infants: a longitudinal study in the first year. Infant Behav Dev. 2011;34:179-188.

74. Korja R, Maunu J, Kirjavainen J, et al. Mother-infant interaction is influenced by the amount of holding in preterm infants. Early Hum Dev. 2008;84:257-267.

75. Hsu HC, Jeng SF. Two-month-olds' attention and affective response to maternal still face: a comparison between term and preterm infants in Taiwan. Infant Behav Dev. 2008;31:194-206.

76. Feldman R, Eidelman AI. Maternal postpartum behavior and the emergence of infant-mother and infant-father synchrony in preterm and full-term infants: the role of neonatal vagal tone. Dev Psychobiol. 2007;49:290-302.

77. Olafsen KS, Rønning JA, Handegård $\mathrm{BH}$, Ulvund SE, Dahl LB, Kaaresen PI. Regulatory competence and social communication in term and preterm infants at 12 months corrected age: results from a randomized controlled trial. Infant Behav Dev. 2012;35:140-149.

78. Landry SH. Preterm infants' responses in early joint attention interactions. Infant Behav Dev. 1986;9:1-14.

79. Davis DW, Burns B, Snyder E, Dossett D, Wilkerson SA. Parent-child interaction and attention regulation in children born prematurely. J Spec Pediatr Nurs. 2004;9:85-94.

80. Rea L, Mamone P, Santirocchi G, Braibanti P. Effetti della marsupioterapia sulle interazioni precoci madre-bambino pretermine. Eta Evol. 1998;62:3-11.

81. Agostini F, Neri E, Dellabartola S, Biasini A, Monti F. Early interactive behaviours in preterm infants and their mothers: influences of maternal depressive symptomatology and neonatal birth weight. Infant Behav Dev. 2014;37:86-93.

82. Schermann-Eizirik L, Hagekull B, Bohlin G, Persson K, Sedin G. Interaction between mothers and infants born at risk during the first six months of corrected age. Acta Paediatr. 1997;86:864-872.

83. Gerner EM. Emotional interaction in a group of preterm infants at 3 and 6 months of corrected age. Infant Child Dev. 1999;8:117-128.

84. Harrison MJ, Magill-Evans J. Mother and father interactions over the first year with term and preterm infants. Res Nurs Health. 1996;19: 451-459.

85. Feldman R. Maternal versus child risk and the development of parentchild and family relationships in five high-risk populations. Dev Psychopathol. 2007;19:293-312.

86. Kmita G, Kiepura E, Majos A. Paternal involvement and attention sharing in interactions of premature and full-term infants with fathers: a brief report. Psychol Lang Commun. 2014;18:190-203.

87. Blanchard C, de Coster L. Quel intérêt pour la recherche et la clinique de mieux comprendre la trajectoire développementale familiale suite à la naissance prématurée d'un enfant? Projet de recherche. Ther Fam. 2013;34:317-332.

88. Treyvaud K, Doyle LW, Lee KJ, et al. Family functioning, burden and parenting stress 2 years after very preterm birth. Early Hum Dev. 2011;87:427-431.

89. Fivaz-Depeursinge E, Corboz-Warnery A. Il Triangolo Primario: Le Prime Interazioni Triadiche tra Padre, Madre, e Bambino. Milan: Raffaello Cortina Editore; 1999.
90. Gueron-Sela N, Atzaba-Poria N, Meiri G, Marks K. The caregiving environment and developmental outcomes of preterm infants: diathesis stress or differential susceptibility effects? Child Dev. 2015;86:1014-1030.

91. Simonelli A, Parolin M, Sacchi C, de Palo F, Vieno A. The role of father involvement and marital satisfaction in the development of family interactive abilities: a multilevel approach. Front Psychol. 2016;7:1725.

92. Landry SH, Smith KE, Swank PR, Assel MA, Vellet S. Does early responsive parenting have a special importance for children's development or is consistency across early childhood necessary? Dev Psychol. 2001;37:387-403.

93. Landry SH, Smith KE, Swank PR. Responsive parenting: establishing early foundations for social, communication, and independent problem solving skills. Dev Psychol. 2006;42:627-642.

94. Simonelli A, Bighin M, de Palo F. Coparenting interactions observed by the prenatal Lausanne trilogue play: an Italian replication study. Infant Ment Health J. 2012;33:609-619.

95. Axia G. QUIT: Questionari Italiani del Temperamento. Trento, Italy: Erickson; 2002.

96. Koren PE, De Chillo N, Friesen BJ. Measuring empowerment in families whose children have emotional disabilities: a brief questionnaire. Rehabil Psychol. 1992;37:305-321.

97. Zimet GD, Dahlem NW, Zimet SG, Farley GK. The multidimensional scale of perceived social support. J Pers Assess. 1988;52:30-41.

98. Guarino A, Di Blasio P, D’Alessio M, Camisasca E, Serantoni G. Parenting Stress Index: Forma Breve. Florence: Giunti Organizzazioni Speciali; 2008.

99. Prezza M, Principato MC. La rete sociale e il sostegno sociale. In: Prezza M, Santinello M, editors. Conoscere la Comunità: Analisi degli Ambienti di Vita Quotidiana. Bologna: Il Mulino; 2002:193-234.

100. Arockiasamy V, Holsti L, Albersheim S. Fathers' experiences in the neonatal intensive care unit: a search for control. Pediatrics. 2008; 121:e215-e222.

101. Vizziello GM, Calvo V. La perdita della speranza: effetti della nascita prematura sulla rappresentazione genitoriale e sullo sviluppo dell'attaccamento. Saggi. 1997;1:15-35.

102. Vizziello GM, Calvo V, Cadrobbi M. Prematurità e psicopatologia in età prescolare: fattori di rischio neonatali e affettivo-relazionali. Psicol Clin Sviluppo. 2000;4:441-463.

103. Speranza AM, Rogora C, Trentini C, Bacigalupi M, Baquè B, Lena F. Interaction between mothers and premature infants during the first two years of life: parental stress and infant emotional-adaptive functioning. Infant Ment Health J. 2010;31 Supp1 1:P321.

104. Vizziello GM. Quando nasceun bambino prematuro. In: Righetti PL, editor. Gravidanza e Contesti Psicopatologici: Dalla Teoria agli Strumenti di Intervento. Milan: Franco Angeli Editore; 2010:164-186.

105. Gatta M, Miscioscia M, Simonelli A, et al. Contribution of analyses on triadic relationships to diagnostics and treatment planning in developmental psychopathology. Psychol Rep. 2017;120:290-304.

106. Gatta M, Miscioscia M, Brianda ME, Simonelli A. Assessment and intervention in mental health services for children and adolescents using the Lausanne trilogue play. Clin Neuropsychiatry. 2017; $14: 216-225$.

107. Gatta M, Ramaglioni E, Lai J, et al. Psychological and behavioral disease during developmental age: the importance of the alliance with parents. Neuropsychiatr Dis Treat. 2009;5:541-546.

108. Gatta M, Dal Zotto L, Nequinio G, et al. Parents of adolescents with mental disorders: improving their caregiving experience. J Child Fam Stud. 2011;20:478-490.

109. Gatta M, Balottin L, Mannarini S, Birocchi V, Del Col L, Battistella PA. Parental stress and psychopathological traits in children and adolescents: a controlled study. Riv Psichiatr. 2016;51:251-259. 


\section{Publish your work in this journal}

Neuropsychiatric Disease and Treatment is an international, peerreviewed journal of clinical therapeutics and pharmacology focusing on concise rapid reporting of clinical or pre-clinical studies on a range of neuropsychiatric and neurological disorders. This journal is indexed on PubMed Central, the 'PsycINFO' database and CAS,

and is the official journal of The International Neuropsychiatric Association (INA). The manuscript management system is completely online and includes a very quick and fair peer-review system, which is all easy to use. Visit http://www.dovepress.com/testimonials.php to read real quotes from published authors.

Submit your manuscript here: http://www.dovepress.com/neuropsychiatric-disease-and-treatment-journal 